\title{
The Stress of Being Chronically Ill: From Disease-Specific to Task-Specific Aspects
}

\author{
Monique Heijmans, ${ }^{1,3}$ Mieke Rijken, ${ }^{1}$ Marleen Foets, ${ }^{1}$ \\ Denise de Ridder, ${ }^{2}$ Karlein Schreurs, ${ }^{2}$ and Jozien Bensing ${ }^{1,2}$
}

Accepted for publication: September 21, 2003

The assumption that disease-related stressors are exclusive for particular diagnoses characterizes many studies of chronically ill patients. In this study the perceptions of 1305 patients from 10 different chronic disease categories were compared with respect to a number of important stressors. Differences were found in the amount and type of stressors experienced, but these differences could not solely be explained by type of disease. Personal characteristics such as age, sex, education level, living situation, and illness duration were also important in determining the degree and type of stress experienced. The implications of these findings for stress/coping research as well as the clinical implications are discussed.

KEY WORDS: chronic diseases; stressors; adaptive tasks; comparison.

\section{INTRODUCTION}

Many people in their mid and late life are confronted with one or more chronic diseases. The most common chronic diseases are not directly fatal (Verbrugge et al., 1989). This means that people must learn to live with a condition over an extended time-course of years without the prospect of recovery. As such, living with a chronic disease imposes many threats and challenges to patients such as dealing with uncertainties about their present and future physical capacities, sustaining relationships with family

\footnotetext{
${ }^{1}$ Nivel, Utrecht, The Netherlands.

${ }^{2}$ Department of Health Psychology, Utrecht University, Utrecht, The Netherlands.

${ }^{3}$ To whom correspondence should be addressed; e-mail: m.heijmans@nivel.nl.
} 
and friends, dealing with pain and other symptoms, and concerns about their abilities to resume their former lifestyle (Devins and Binik, 1996; Moos and Schaeffer, 1984). These consequences of suffering from a chronic disease can be studied by the perspective of stressful situations. That is, a chronic disease may be viewed as a major stressful life event, characterized by a number of recurrent stressful situations, that pose serious challenges to adaptation (Ridder et al., 1998; Moos and Schaeffer, 1984; Zautra, 1996). Chronically ill patients have to cope with these stressful situations and, depending on the results of their coping efforts, they may be able to maintain adequate levels of physical, social, and emotional functioning.

Inspired by the stress-coping model of Lazarus (Lazarus and Folkman, 1984) much research has been done on coping and adjustment of patients with chronic conditions (for a review see Ridder and Schreurs, 1996; Maes et al., 1996). Although this research has provided valuable insights into the ways patients cope with their chronic illness and the effects of coping on chronic illness adjustment, it is difficult to determine the precise value of such a wealth of information for different chronic conditions. One important reason for this is that most research on coping and adjustment to chronic illness is specific to particular diseases and similarities and dissimilarities across different illness conditions have hardly been studied. Patients with a particular disease (e.g. diabetes, multiple sclerosis, or asthma) are typically compared with normal populations or with subpopulations within the same diagnostic category (Cassileth et al., 1984; Clark et al., 1991; Maes et al., 1996). What results are lists of stressors and a notion of coping responses that are specific to a particular disease. Little is known about how various chronic diseases differ or resemble each other in the degree and type of stressors they inflict on people (Cassileth et al., 1984; Ridder and Schreurs, 1996). This lack of knowledge about the specifity or genericity of stressors in chronic disease is an important limitation, since differences in the type and amount of stressors experienced can explain differences in the use of coping strategies and their effectiveness as is shown in the rare studies comparing different chronic conditions. For example, Felton et al. (1984) found differences in the use of coping strategies by patients with diseases varying in controllability (hypertension, diabetes, cancer, and rheumatoid arthritis). In a study by Feifel et al. (1987) it was found that patients suffering from life-threatening diseases (i.e. cancer and myocardial infarction) used confrontation as a coping strategy significantly more than did non life-threatened patients (e.g. arthritis, dermatitis) in dealing with their illness. In studies of Heim et al. (1987) on breast cancer patients and of Warren et al. (1991) on multiple sclerosis, both chronic disorders with an unpredictable course, it was the extent of perceived unpredictability that influenced the choice of coping responses. The results of these studies suggest that the coping behaviors which people use and their 
successfulness seem to be determined by the nature of the stressor with which they are contending and by the subjective experience of this stressor by the patient (Carver and Scheier, 1994; Mattlin et al., 1990). Not the disease per se, but rather the presence or absence of certain disease characteristics seems to determine the degree and type of stress and the coping responses needed. Studies on the stressors related to particular diseases like rheumatoid arthritis (Lankveld et al., 1993), cancer (Dunkel-Schetter et al., 1992), or diabetes (Nouwen et al., 1997) confirm these findings and show that the type and degree of stress may vary according to specific disease characteristics such as the availability of adequate treatment possibilities, the amount of life-threateningness, and the physical impairments caused by the disease. Within this framework then, it seems important to gain better insight into the type of stressors experienced by patients suffering from different chronic diseases and into their similarities and dissimilarities as information on the nature of disease-related stressors may contribute to a better understanding of the coping attempts of patients suffering from chronic disease.

The present study was designed to provide an overview and comparison of the way stressors are experienced by patients with different chronic diseases. More specifically, we would like to know if stressors that have been identified in the literature on chronic disease, are indeed experienced by patients of different chronic conditions and if so, to what extent. For this purpose, we selected 10 diseases that all have a high prevalence in the general population and are significant in terms of their impact on daily life and the adjustment they demand: Ischemic Heart Disease (IHD), Chronic Obstructive Pulmonary Disease (COPD), asthma, rheumatoid arthritis (RA), osteoarthritis, cancer, diabetes mellitus, progressive neurological diseases (PND), migraine, and gastrointestinal diseases. It was hypothesized that these chronic diseases, although different in biological backgrounds, would share a number of important disease characteristics, and as such impose many common stressors and demands for coping upon patients. As it is likely that stressors are perceived differently by patients depending on personal circumstances as age, living situation, education level, and illness duration, the influence of these characteristics on the perception of disease-related stressors was also assessed.

\section{METHOD}

\section{Sample}

The sample consisted of 1305 chronic disease patients, distributed over 10 disease categories: Ischemic Heart Disease (IHD, $n=76$ ) including 
patients with Ischemic Heart Disease with and without angina and patients with acute myocardial infarction, Chronic Obstructive Pulmonary Disease (COPD, $n=162)$, asthma ( $n=179)$, Rheumatoid Arthritis (RA, $n=96$ ), osteoarthritis $(n=135)$, cancer $(n=120)$ including predominantly patients with cancer in blood and blood-forming organs, digestive organs, lungs, kidney and bladder, breasts and prostate, diabetes mellitus $(n=292)$, Progressive Neurological Diseases (PND, $n=103$ ) including multiple sclerosis, parkinsonism and neuropathy, migraine $(n=67)$, and gastrointestinal diseases $(n=75)$ including divertical disease, chronic enteritis, and liver disease. Only patients suffering from one chronic disease were included. Patients with comorbidity were excluded from this study. All patients were selected from a larger database $(n=2736)$ of the "Panel of Patients with Chronic Diseases," a longitudinal study on chronic disease patients conducted by NIVEL (Netherlands Institute for Health Services Research) ${ }^{4}$ All patients participating in this panel are randomly selected via one of 56 general practitioners' practices in the Netherlands according to the following criteria: a diagnosis of a noncurable chronic disease by a certified medical practitioner, an age $\geq 15$, being noninstitutionalized, being aware of diagnosis, not being terminally ill (life-expectancy $>1$ year according to the GP), being mentally and physically able to participate, and a sufficient mastery of the Dutch language. Treated cancer patients who were symptom-free after 5 years are excluded from the panel.

\section{Measures}

\section{Demographic Characteristics}

Patients were asked about their age, gender, highest level of education, and marital status. Because of the small percentages of patients who were living alone, divorced, or widowed, marital status was dichotomized in living with a partner/living alone. Education level was divided into three categories: low (vocational training), middle (high school), and high (college or university).

\section{Disease-Related Characteristics}

Patients were classified by their general practitioner (GP) according to their diagnosis using the International Classification of Primary Care

${ }^{4}$ For background, aim, design, and selection procedures of this study see Rijken and Bensing (2000). 
(Lamberts and Wood, 1987). In addition, questions were answered about illness duration by the GP at inclusion.

\section{Chronic Disease Stressors}

For our choice of items to assess stressors in chronic disease, we followed the definition of adaptive tasks as formulated by De Haes et al. (1997). According to this definition adaptive tasks are those characteristics of an individual's situation that are changed by a chronic disease and that require adaptation of the person in order to maintain quality of life or at least to minimize damage. On the one hand, adaptive tasks refer to stressful physical or psychological characteristics of the disease such as threat of life or pain, on the other hand they refer to the stressful consequences of the disease in terms of disability in physiological, psychological, and social functioning. The stressors used in this study were: life-threatening, progressive deterioration, intermittent character, controllability by medical care, controllability by self-care, pain, fatigue, visible changes of the body, physical disability, social disability, and mental disability. These stressors have been identified as general themes where chronic patients refer to when asked for the consequences of their disease (e.g. Felton et al., 1984; Heim et al., 1987; Moos and Schaeffer, 1984; Ridder et al., 1998). Patients rated on a 3-point scale $(1=$ not at all, $2=$ to a certain extent, $3=$ to a large extent $)$ in what way their illness was characterized by each of these stressors.

\section{Coping}

Coping was assessed by the shortened Dutch version of the Coping Inventory for Stressful Situations (CISS-21, Endler and Parker, 1999), consisting of 21 items and measuring three dimensions of coping: task-oriented coping ( 7 items, e.g. "Focus on the problem and see how I can solve it"), emotion-oriented coping ( 7 items, e.g. "Feel anxious about not being able to cope"), and avoidance-oriented coping ( 7 items, e.g. "Take some time off and get away from the situation"). Respondents are asked to rate each item on a 5-point frequency scale ranging from (1) Not at all to (5) Very much. The CISS has been applied to several groups of chronically ill patients and proven to be a reliable and valid instrument (Endler and Parker, 1994).

\section{Analysis}

Data were analyzed by means of analysis of variance, using the Scheffé procedure, a two-tailed test for all possible comparisons among means that 
corrects significance levels obtained with the multiple analysis of variance technique. In order to reduce the possibility of Type 1 errors, a significance level of 0.01 was adopted for all calculations. To explore the presence of meaningful subgroups of stressors across diseases a $k$-means cluster analysis (QUICKCLUSTER Procedure, Spss/PC+ Professional Statistics, Norusis, 1992) was conducted. This procedure, which is based on Euclidian distances, consists of dividing patients into clusters such that every patient belongs to one and only one cluster.

\section{RESULTS}

\section{Demographics}

The demographic and disease-related characteristics of the different diagnostic groups are presented in Table I. One-way ANOVAs revealed some significant differences with respect to age $(F(9,1275)=31.34, p<$ $0.001)$ and illness duration $(F(9,1267)=7.09, p<0.001)$. Patients with IHD, osteoarthritis, and COPD were significantly older than most other patients, whereas asthma patients were significantly younger. No group of patients differed significantly from any other group on the time they were ill, except for cancer patients and to a lesser extent IHD patients: As compared to patients with COPD, asthma, migraine, and RA, cancer patients and IHD patients were ill for a significantly shorter period of time. Comparisons with $\chi^{2}$ tests revealed significant differences in sex distribution

Table I. Demographic and Disease-Related Characteristics According to Diagnosis

\begin{tabular}{|c|c|c|c|c|c|c|c|}
\hline \multirow[b]{2}{*}{ Diagnosis } & \multirow{2}{*}{$\begin{array}{c}\text { Age } \\
\text { M(SD) }\end{array}$} & \multirow{2}{*}{$\begin{array}{l}\text { Women } \\
\%\end{array}$} & \multicolumn{3}{|c|}{ Education level } & \multirow{2}{*}{$\begin{array}{c}\text { Married } \\
\%\end{array}$} & \multirow{2}{*}{$\begin{array}{l}\text { Illness duration } \\
\mathrm{M}(\mathrm{SD})\end{array}$} \\
\hline & & & Low \% & Middle \% & High \% & & \\
\hline IHD $(n=76)$ & $63.4(11.2)$ & 26 & 42 & 44 & 14 & 81 & $6.6(6.0)$ \\
\hline $\operatorname{COPD}(n=162)$ & $62.0(15.2)$ & 47 & 47 & 41 & 12 & 78 & $10.8(7.3)$ \\
\hline Asthma $(n=179)$ & $42.5(15.3)$ & 62 & 34 & 48 & 18 & 73 & $10.4(8.0)$ \\
\hline RA $(n=96)$ & $52.3(14.1)$ & 72 & 41 & 40 & 19 & 83 & $10.4(7.8)$ \\
\hline $\begin{array}{l}\text { Osteoarthritis } \\
(n=135)\end{array}$ & $63.8(12.3)$ & 63 & 47 & 45 & 8 & 74 & $8.3(7.9)$ \\
\hline $\begin{array}{l}\text { Diabetes mellitus } \\
\quad(n=292)\end{array}$ & $57.8(15.2)$ & 50 & 51 & 34 & 15 & 78 & $9.0(8.6)$ \\
\hline $\operatorname{PND}(n=103)$ & $56.6(15.1)$ & 57 & 45 & 42 & 13 & 72 & $8.8(10.3)$ \\
\hline Migraine $(n=67)$ & $47.3(12.5)$ & 83 & 29 & 52 & 19 & 77 & $10.8(11.8)$ \\
\hline $\begin{array}{l}\text { Gastrointestinal } \\
\text { disorders } \\
(n=75)\end{array}$ & $52.4(17.0)$ & 77 & 52 & 41 & 7 & 82 & $7.3(6.5)$ \\
\hline Cancer $(n=120)$ & $58.7(13.8)$ & 54 & 53 & 37 & 10 & 85 & $4.6(4.5)$ \\
\hline
\end{tabular}


$(\chi(9,1285)=85.41, p<0.001)$, and education level $(\chi(18,1214)=32.20$, $p<0.001)$. As can be seen from Table I, the majority of patients in each disease group was female except for IHD and to a lesser extent COPD and diabetes mellitus. Inspection of Table I shows patients with asthma, RA, and migraine to be somewhat higher educated. The disease categories did not significantly differ with respect to marital status.

\section{Chronic-Disease Stressors}

Mean scores and standard-deviations on the chronic-disease stressors for the different disease categories are presented in Table II. One-way ANOVAs followed by Scheffé-tests (0.01) yielded significant differences between the diagnostic groups. Three stressors were related to the expected course of the illness: life-threatening, progressive deterioration, and intermittent character. In general, patients in this study did not view their illness as very threatening for life. Only patients suffering from IHD and cancer perceived their illness as significantly more life-threatening than patients from any of the other disease categories. With respect to progressive deterioration, RA patients and patients with PND, COPD, or osteoarthritis were significantly more convinced that their illness would worsen over time than patients suffering from gastrointestinal diseases, migraine, asthma, and cancer. In addition, RA patients perceived the course of their illness as significantly less stable (intermittent character) than patients with cancer, IHD, and diabetes, who considered the course of their illness to be rather stable. Two stressors were related to the controllability of illness: controllable by medical care and controllable by self-care. Patients from all disease categories scored quite high on both variables indicating that they perceived their illness as rather controllable. In fact, with the exception of osteoarthritis patients and patients suffering from PND, no group of patients significantly differed from any of the other groups on both variables. Both osteoarthritis patients and patients suffering from PND perceived the controllability of their illness by a physician as significantly less than patients with COPD, asthma, IHD, and diabetes who had more confidence in the treatment possibilities of their doctors. With respect to controllability by self-care the only difference was between osteoarthritis patients and PND patients on the one side and asthma and diabetes patients on the other side, the latter two perceiving their illness as far more controllable by own behavior. The remaining stressors all are related to some extent to the stressful consequences of a chronic disease for daily life. With respect to pain, not surprisingly, patients suffering from RA, osteoarthritis, and migraine reported significantly more pain as compared to the other diagnostic groups. RA and osteoarthritis patients also 


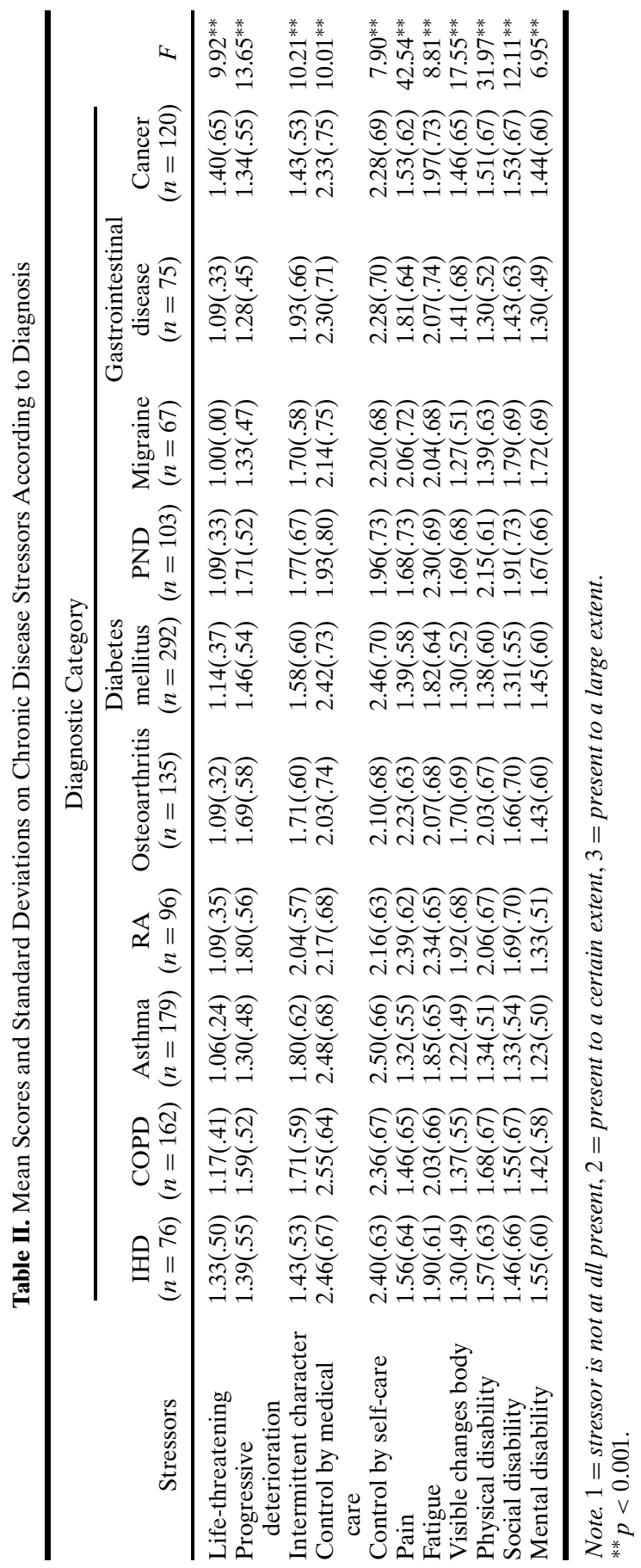


indicated to experience more visible bodily changes than patients from the other diagnostic categories. More specifically, RA patients reported more changes than any of the other patient groups whereas osteoarthritis patients reported significantly more changes than patients suffering from asthma, IHD, migraine, diabetes, and COPD. Patients with PND reported more visible bodily changes than patients suffering from asthma, IHD, and diabetes. All patient groups scored rather high on "fatigue." ANOVAs yielded no difference between the 10 disease groups except for RA patients and patients with PND who both indicated to be significantly more tired than patients with diabetes and asthma. With respect to physical disability, social disability, and mental disability ANOVAs roughly show the following picture: Patients with RA, osteoarthritis, and PND perceived their illness as most disabling for physical functioning and differed in this respect significantly from most of the other disease categories. In general, scores on mental and social functioning were low. No differences were found between any of the disease groups on these two variables, except for patients suffering from diabetes and asthma. Patients with diabetes perceived the consequences of their illness for social functioning as less serious when compared to patients with PND, migraine, and RA. Asthma patients seem to experience significantly fewer mental health problems when compared to patients suffering from migraine, PND, and IHD.

To summarize, ANOVAs yielded some significant differences on the stressors between the different diagnostic groups. However, the differences always concern one or two disease categories and do not discriminate between all 10 disease categories. Because of that, the results comprise no convincing evidence for the disease-exclusivity of these stressors. It appeared that patients of different disease categories as a group hardly differed in their perception of the presence of stressors such as life-threatening, progressive deterioration, controllability, and fatigue. The differences that exist did not occur systematically between diagnostic groups and some diseaserelated stressors seem to discriminate better than others. Therefore, it might be better not to focus on possible differences in separate stressors between diseases, but rather on possible differences in the patterns formed by these stressors.

The next step, then, will be to identify conceptually meaningful subgroups of patients based on their scores on the 11 disease-related stressors. Cluster analysis revealed a four-cluster solution as the optimal number of clusters $^{5}$ that could explain the profile structure of the patients' scores on

${ }^{5}$ In order to determine the number of clusters and to check the internal consistency of the cluster solution a cluster analysis was performed on three different subsamples of the total sample of 1305 patients. The same four clusters appeared in the three solutions. 


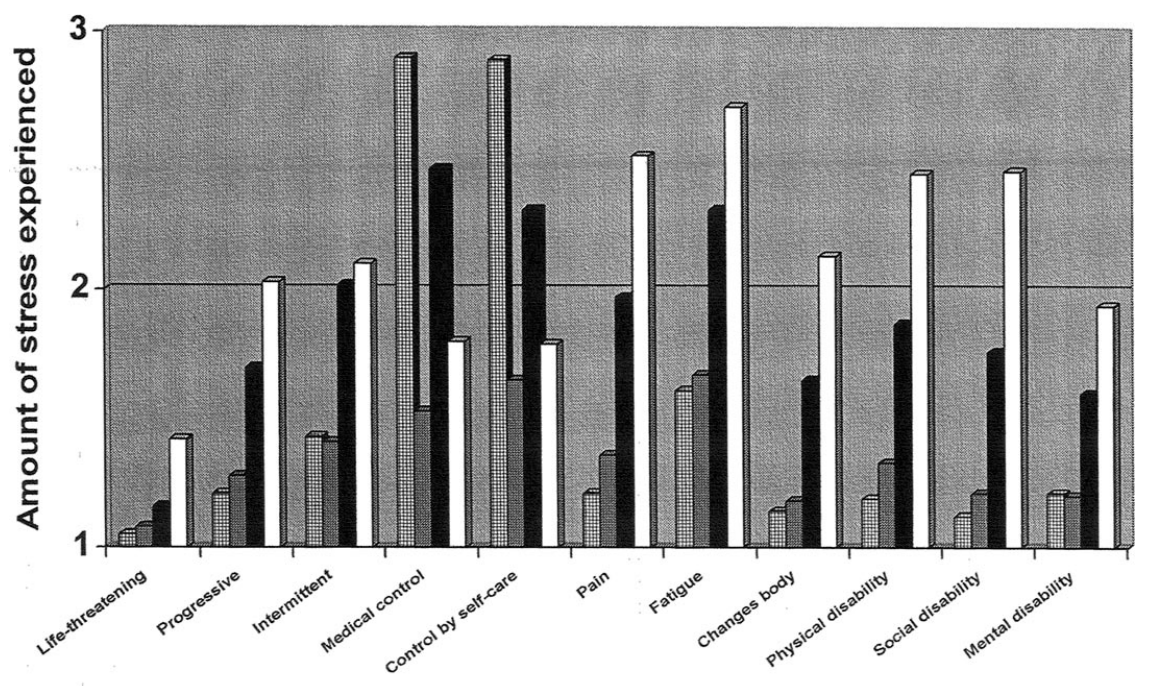

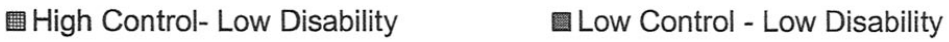

- Moderate Control - Moderate Disability $\square$ Low Control - High Disability

Fig. 1. Clustering of Chronic Disease Stressors Across Diagnoses.

disease-related stressors. The mean $T$-scores for the four clusters on the 11 stressors are plotted in Fig. 1. Univariate ANOVAs were computed, followed by Scheffé tests $(p=0.01)$. As can be seen from Table III, significant cluster differences were found on all 11 stressors. Four variables in particular seem to discriminate between the four clusters: the extent to which the patient perceives the illness as controllable by either a medical care or selfcare, the perceived painfullness of the illness, and the perceived physical consequences.

\section{Description of the Clusters}

\section{High Control—Low Disability (HC-LD Cluster)}

This cluster contains 452 patients or $35 \%$ of the sample. Patients in this cluster appear to view their illness as less threatening and distressing than patients in the other clusters. Scheffé-tests showed that patients in this cluster believed their illness to be far more controllable by medical care and selfcare, and that they reported significantly less pain and interference of their illness with respect to physical function than patients in the other clusters. 


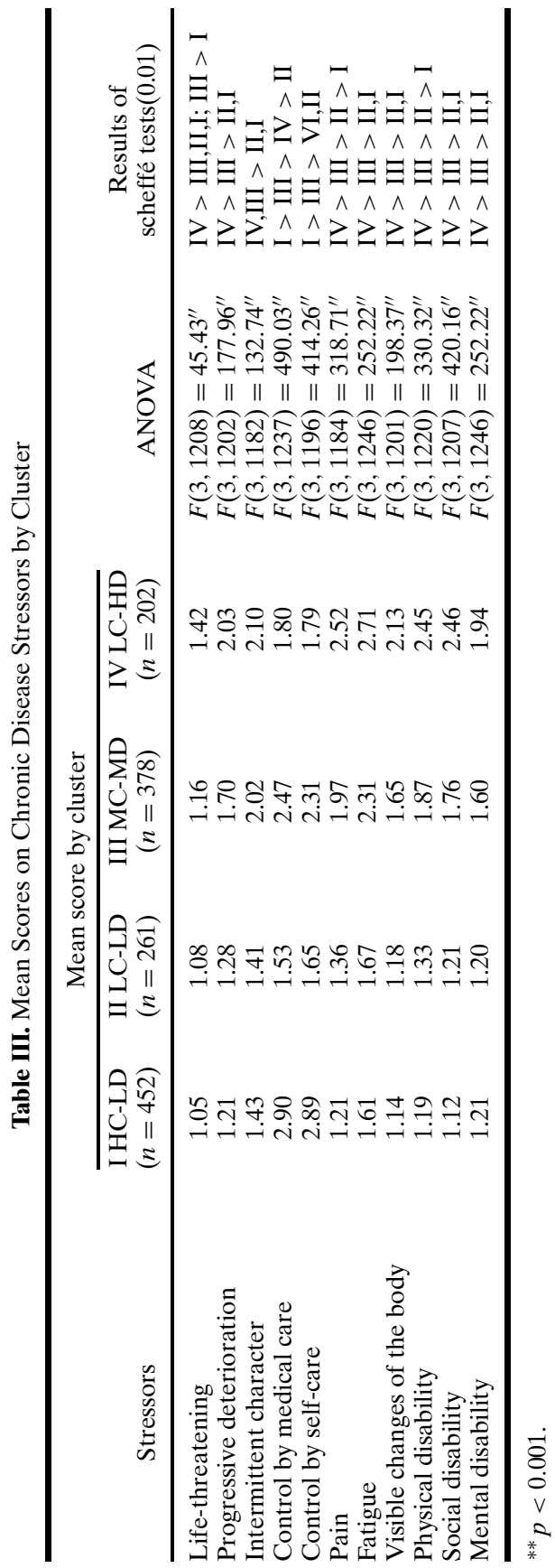




\section{Low Control—Low Disability (LC-LD Cluster)}

Patients $(n=261)$ in this cluster, which contains $20.1 \%$ of the sample, resemble patients in the HC-LD Cluster as far as their perceptions of the time course and of the limitations of their illness for daily life are concerned: Patients in both clusters describe the course of their illness as rather stable with only minimal complications for daily life. However, whereas patients in the HC-LD Cluster view their illness as highly controllable, patients in the LC-LD Cluster believe significantly less in the possibilities for control by medical care or self-care.

\section{Moderate Control-Moderate Disability (MC-MD Cluster)}

Patients $(n=378)$ in this cluster, constituting $29.2 \%$ of the total sample, judge their illness as rather painful, accompanied by physical impairments and fatigue, changing in course, but despite these facts, rather controllable by a medical specialist and self-care.

\section{Low Control—High Disability (LC-HD Cluster)}

Patients $(n=202)$ in this last cluster, which contains $15.6 \%$ of the sample, have in common the perception that their illness is progressive, rather uncontrollable, and brings about severe limitations for daily life. ANOVAs indicated that patients in this cluster perceive their illness as significantly more life-threatening, changing, and worsening over time than patients in the other clusters. They also report more pain, fatigue, visible physical changes, physical impairments, social impairments, and mental impairments than patients in the other clusters.

Table IV shows the distribution of the 10 disease categories across clusters. Although some diagnostic patient groups seem to be more often part of one particular cluster-almost half of the patients with IHD, asthma, and diabetes mellitus fall into the HC-LD cluster, whereas $44 \%$ of the RA patients fall into the MC-MD cluster-generally, patients of the different disease categories are present in all of the four clusters, showing individual variation within patients suffering from the same disease.

\section{Clustermembership in Relation to Disease-Related and Demographic Variables}

Differences in demographic or disease-related variables between the clusters were explored using univariate ANOVAs and $\chi^{2}$ analysis. 
Table IV. Distribution of the Diagnostic Categories Across Clusters

\begin{tabular}{lcccc}
\hline & \multicolumn{4}{c}{ Clustermembership (\%) } \\
\cline { 2 - 5 } Diagnostic category & Cluster HC-LD & Cluster LC-LD & Cluster MC-MD & Cluster LC-HD \\
\hline IHD $(n=74)$ & 42 & 16 & 34 & 8 \\
COPD $(n=161)$ & 39 & 13 & 34 & 14 \\
Asthma $(n=179)$ & 50 & 22 & 25 & 3 \\
RA $(n=96)$ & 15 & 7 & 44 & 34 \\
Osteo-arthritis & 15 & 21 & 30 & 34 \\
$\quad(n=130)$ & 46 & 23 & 24 & 7 \\
Diabetes $(n=291)$ & 12 & 24 & 33 & 31 \\
PND $(n=102)$ & 27 & 19 & 34 & 19 \\
Migraine $(n=67)$ & 27 & 36 & 14 & 23 \\
Gastrointestinal & & & & \\
$\quad$ disorders $(n=75)$ & 37 & 27 & 21 & 15 \\
Cancer $(n=118)$ & &
\end{tabular}

\section{Demographic Variables}

Significant differences were found between the clusters regarding age, $F(3,1271)=5.4, p<0.001$. Scheffé tests showed that patients in the LC-HD Cluster were significantly older than patients in the HC-LD Cluster, whereas patients in the other clusters did not significantly differ. An ANCOVA analysis with the disease-related stressors as dependent variables, clustermembership as independent variables, and age as a covariate indicated that cluster differences on all disease-related stressors remained after controlling for age except for perceived painfulness, perceived social disabilities, and fatigue. $\chi^{2}$ analysis also indicated significant differences between the clusters regarding gender, $\chi^{2}(3,1775)=10.59, p<0.01$, and education level $\chi^{2}(6,1207)=20.73, p<0.001$. Inspection of Table $\mathrm{V}$ showed patients in the MC-MD Cluster and in the LC-HD Cluster to contain more women than patients in the other two clusters. Patients in the HC-LD Cluster were somewhat higher educated.

Table V. Demographic and Disease-Related Characteristics According to Cluster

\begin{tabular}{|c|c|c|c|c|c|c|c|}
\hline \multirow{2}{*}{$\begin{array}{l}\text { Type of } \\
\text { cluster }\end{array}$} & \multirow{2}{*}{$\begin{array}{l}\text { Age } \\
\mathrm{M}(\mathrm{SD})\end{array}$} & \multirow[b]{2}{*}{ Women \% } & \multicolumn{3}{|c|}{ Education level } & \multirow[b]{2}{*}{ Married \% } & \multirow{2}{*}{$\begin{array}{c}\text { Illness } \\
\text { duration } \mathrm{M}(\mathrm{SD})\end{array}$} \\
\hline & & & Low \% & Middle \% & High \% & & \\
\hline HC-LD & $53.6(16.0)$ & 52 & 38 & 45 & 17 & 81 & $8.5(7.6)$ \\
\hline LC-LD & $56.0(15.8)$ & 56 & 48 & 38 & 14 & 78 & $8.4(8.6)$ \\
\hline MC-MD & $56.5(16.6)$ & 60 & 45 & 43 & 12 & 76 & $9.8(8.9)$ \\
\hline LC-HD & $58.8(14.3)$ & 64 & 56 & 35 & 10 & 77 & $8.9(8.2)$ \\
\hline
\end{tabular}




\section{Disease-Related Variables}

ANOVAs showed no significant difference between the clusters in illness duration.

\section{External Cluster Validation}

As we expected that differences in disease-related stressors would bring about differences in coping behavior of chronically ill patients, the four clusters were compared on the three scales of the CISS (task-oriented coping, emotion-oriented coping, and avoidance-oriented coping). Univariate ANOVAs were computed, followed by Scheffé tests (0.01). As can be seen from Table VI, significant cluster differences were found on all three variables. Patients in the clusters where disability was moderate or high (MC-MD Cluster and LC-HD) used significantly more emotion-oriented coping strategies than patients in clusters where disability was low (HC-LD Cluster and LC-LD Cluster). Patients in the LC-HD Cluster also used more taskoriented and avoidance-oriented coping strategies than patients from the LC-LD Cluster. These results then, provide evidence that the patient clusters are specific and distinct.

\section{DISCUSSION}

This study was designed to gain better insight into the type of stressors experienced by patients suffering from different chronic diseases and into their similarities and dissimilarities. Before discussing the results of this study, some methodological issues have to be considered. First, the information in this study about the presence of chronic disease stressors as well as the information on coping used for external validation of the clusters,

Table VI. Mean Scores and Standard Deviations on the Three Scales of the CISS for Each Cluster

\begin{tabular}{|c|c|c|c|c|c|c|c|}
\hline \multirow[b]{2}{*}{$\begin{array}{l}\text { Coping } \\
\text { strategies }\end{array}$} & \multicolumn{4}{|c|}{ Mean score (SD) by cluster } & \multirow[b]{2}{*}{ df's } & \multirow[b]{2}{*}{$F$} & \multirow[b]{2}{*}{$\begin{array}{c}\text { Results of } \\
\text { Scheffé tests } \\
(0,01)\end{array}$} \\
\hline & $\begin{array}{c}\mathrm{I} \\
\text { HC-LD } \\
(n=452)\end{array}$ & $\begin{array}{c}\text { II } \\
\text { LC-LD } \\
(n=261)\end{array}$ & $\begin{array}{c}\text { III } \\
\text { MC-MD } \\
(n=378)\end{array}$ & $\begin{array}{c}\text { IV } \\
\text { LC-HD } \\
(n=202)\end{array}$ & & & \\
\hline CISS- 1 & $.0(8.1)$ & $19.0(8.1)$ & $21.0(7.6)$ & $22.2(7.3)$ & 3,928 & $4.5^{\prime \prime}$ & $\mathrm{IV}>\mathrm{II}$ \\
\hline CISS-emotion & $13.7(5.7)$ & $14.0(6.6)$ & $17.6(7.0)$ & $18.1(7.1)$ & 3,935 & $22.5^{\prime \prime}$ & IV, III >II,I \\
\hline CISS-avoidant & $14.0(6.5)$ & $13.0(6.0)$ & $14.5(6.0)$ & $15.2(6.5)$ & 3,939 & $3.8^{\prime}$ & IV $>$ II \\
\hline
\end{tabular}

${ }^{*}=p<0.01 ; * *=p<0.001$. 
were largely based on self-report measures. Validation of the cluster solution would have been stronger if additional medical measures were included. Second, using the criteria of "not being terminally ill" to select patients for this study has a consequence that the results cannot be generalized to all chronic disease patients. Patients in this study were those with a relatively good prognosis. Because of this, especially the group of cancer patients may not be representative. Despite these methodological shortcomings, this study yielded a number of interesting findings.

The central question of the present study was whether disease-related stressors would be exclusive for particular diseases, or if it would be possible to identify a generic set of stressors that patients have to cope with, regardless of disease. Our results clearly show that the chronic conditions in this study have many general stressors in common. Despite wide variation in biological backgrounds and medical treatment, patients of the different diagnostic categories hardly differ in their perceptions of a number of important stressors such as life-threateningness, progressive deterioration, controllability and fatigue. Differences in the degree and type of stressors exist, as was shown by the cluster solutions, but these differences cannot be solely explained by type of disease. Personal characteristics such as gender, age, living situation, and education level seem to be important as well.

The importance of personal circumstances on the subjective evaluation of problems caused by disease has been stressed by many authors (Bombardier et al., 1990; Leventhal et al., 1997; Maes et al., 1996). In this study, patients in Clusters III and IV, those clusters characterized by high levels of disabilities, contained more patients who were female, older, not married, less educated, and ill for a longer period of time. These are vulnerable people who deserve attention and consideration, both in research and in clinical practice.

Our choice to define disease-related stressors in this study as objectively defined problem categories posed by a chronic disease as a medical entity needs some further consideration. It is our opinion that chronic diseases, as compared to acute diseases, bring about stressors that are common to all chronic conditions, independent of diagnosis. Of course, the content of the stressors may differ. For example, patients with diabetes have to monitor their blood glucose levels, whereas patients with asthma have to monitor oneself to note changes in respiratory values. Although different in behavior, the essential nature of the task is the same, however. In the case of both diabetes and asthma, one must be aware of the link between certain health behaviors and dangerous health consequences. Viewing chronic disease stressors as a set of basic tasks patients have to cope with, that cut across chronic conditions, has both theoretical and practical relevance. Theoretically, it makes comparisons across diseases possible and provides insight into 
the generalizability of findings on stress and coping related to specific disease categories. Practically, if common stressors can be identified and elaborated, the potential for providing effective education and support programs is greatly increased. As stated earlier, research on particular chronic diseases diseases exists largely in isolation, lacking information about analogous data on patients with other chronic diseases (Heijmans et al., 1998). For example, identification of the problems and the development of intervention strategies for patients with rheumatoid arthritis occurs within the realm of that speciality (Cassileth et al., 1984; Clark et al., 1991), with little known about how RA patients differ, for example, from patients with diabetes or heart failure. If a core of common tasks exist among conditions, as is suggested by the results of this study, institutions might devote their resources to a single comprehensive program. This may become even more important, as in our aging society, the number of patients with multimorbidity and complex problems will increase.

\section{ACKNOWLEDGMENT}

We would like to thank Joost Dekker, Julia van Weert, and Mirjam Westenberg for their comments on an earlier version of this article.

\section{REFERENCES}

Bombardier, C. H., D'Amico, C., and Jordan, J. S. (1990). The relationship of appraisal and coping to chronic disease adjustment. Behav. Res. Ther. 28: 297-304.

Carver, C. S., and Scheier, M.F. (1994). Situational coping and coping dispositions in a stressful transaction. J. Pers. Soc. Psychol. 66: 184-195.

Cassileth, B. R., Lusk, E. J., Strouse, T. B., Miller, D. S., Brown, L. L., Cross, P. A., and Tenaglia, A. N. (1984). Psychosociale status in chronic illness. A comparative analysis of six diagnostic groups. N. Engl. J. Med. 311: 506-511.

Clark, N. M., Becker, M. H., Janz, N. K., Loring, K., Rakowski, W., and Anderson, L. (1991). Self-management of chronic disease by older adults. J. Aging Health 3: 3-27.

Devins, G. M., and Binik, Y. M. (1996). Facilitating coping with chronic physical illness. In Zeidner, M., and Endler, N. (Eds.), Handbook of Coping: Theory, Research and Applications, New York, Wiley, pp. 640-696.

Dunkel-Schetter, C., Feinstein, L. G., Taylor, S. E., and Falke, L. R. (1992). Patterns of coping with cancer. Health Psychol. 11: 79-87.

Endler, N. S., and Parker, J. D. A. (1994). Assessment of multidimensional coping: Task, emotion, and avoidance strategies. Psychol. Assess. 6(1): 50-60.

Endler, N. S., and Parker, J. D. A. (1999). Coping Inventory for Stressful Situations (CISS)— Manual, Multi-Health Systems, Toronto, Canada.

Feifel, H., Strack, S., and Tong Nagy, V. (1987). Degree of life-threat and differential use of coping modes. J. Psychosom. Res. 31: 91-99.

Felton, B., Revenson, T. A., and Hinrichsen, G. A. (1984). Stress and coping in the explanation of psychological adjustment among chronically ill adults. Soc. Sci. Med. 18: 889-898. 
Haes, J. C. J. M. de, Sprangers, M. A. G., Regt, H. B. de, Andries, F., et al. (1997). Adaptive Tasks in Chronic Disease, NWO, Den Haag, Amsterdam.

Heijmans, M., Ridder, D. de, Schreurs, K., and Sorbi, M. (1998). Psychosociale zorg aan somatisch chronisch zieken: Een inventarisatie van de mogelijkheden voor richtlijnontwikkeling, Utrecht, The Netherlands.

Heim, E., Augustiny, K., Blaser, A., Bürki, C., Kühne, D., Rothenbühler, M., Schaffner, L., and Valach, L. (1987). Coping with breast cancer; A longitudinal prospective study. Psychother. Psychosom. 48: 44-59.

Lamberts, H., and Wood, M. (1987). ICPC. International Classification of Primary Care, Oxford University Press, Oxford.

Lankveld, W. van, Naring, G., Staak, C. van, 't Pad Bosch, P. van, and Putte, L. van (1993). Stress caused by rheumatoid arthritis: Relation among subjective stressors of the disease, disease status, and well-being. J. Behav. Med. 16: 309-321.

Lazarus, R. S., and Folkman, S. (1984). Stress, Appraisal and Coping, Springer, New York.

Leventhal, H., Benyamini, Y., Brownlee, S., Diefenbach, M., Leventhal, E. A., Patrick-Miller, L., and Robitaille, C. (1997). Illness representations: Theoretical foundations. In Petrie, K. J., and Weinman, J.(Eds.), Perceptions of Health and Illness, Harwood Academic, Amsterdam, pp. 19-47.

Maes, S., Leventhal, H., and Ridder, D. T. D. de (1996). Coping with chronic diseases. In Zeidner, M., and Endler, N. (Eds.), Handbook of Coping: Theory, Research and Applications, Wiley, New York, pp. 221-251.

Mattlin, J. A., Wethington, E., and Kessler, R. C. (1990). Situational determinants of coping and coping effectiveness. J. Health Soc. Behav. 31: 103-122.

Moos, R. H., and Schaeffer, J. A. (1984). The crisis of physical illness. An overview and conceptual approach. In Moss, R. M. (Ed.), Coping With Physical Illness, Vol. 2, New Perspectives, Plenum Press, New York, pp. 3-39.

Norusis, M. J. (1992). SPSS/PC+, Professional Statistics-Version 5, SPSS, Chicago.

Nouwen, A., Gingras, J., Talbot, F., and Bouchard, S. (1997). The development of an empirical taxonomy for patients with diabetes. Health Psychol. 16: 263-271.

Ridder, D. de, and Schreurs, K. (1996). Coping, social support and chronic disease: A research agenda. Psychol. Health Med. 1: 71-82.

Ridder, D. T. D. de, Schreurs, K. M. G., and Bensing, J. M. (1998). Adaptive tasks, coping and quality of life of chronically ill patients. The cases of Parkinson 's Disease and the Chronic Fatigue Syndrome. J. Health Psychol. 3: 87-101.

Rijken, M., and Bemsing, J. (2000). Het nationaal Patientenpanel Chronisch Zieken. Een onderzoeksinfrastructuur voor patientgericht onderzock. TSG 2: 93-100.

Verbrugge, L. M., Lepkowski, J. M., and Imanaka, Y. (1989). Comorbidity and its impact on disability. Milbank Q. 67: 450-484.

Warren, S., Warren, K., and Cockerill, R. (1991). Emotional stress and coping in multiple sclerosis exarcebations. J. Psychosom. Res. 35: 37-47.

Zautra, A. J. (1996). Investigations of the ongoing stressful situations among those with chronic illness. Am. J. Commun. Psychol. 24: 697-717. 